\title{
NOSSO PAI, NOSSO DONO: RELAÇÕES DE MAESTRIA ENTRE OS MBYA GUARANI ${ }^{1}$
}

\author{
Vicente Cretton Pereira
}

\section{Introdução}

No texto a seguir desenvolvo uma leitura da relação dos Mbya Guarani e suas divindades a partir do idioma das relações de maestria, o qual ao designar um laço que envolve controle, proteção e cuidado (Costa 2013:473) coloca a predação às avessas sem com isso ser o avesso da predação. Tratar-se-á então tanto de perceber os deuses enquanto donos dos humanos, quanto de compreender a agência dos termos implicados na relação de maestria: dono (-ja) e seu recíproco animal de estimação (mymba, ou xerimbabo, tal como aparece comumente na literatura). No âmbito da etnologia das terras baixas, provocou-me a difundida noção de perspectiva (ver Viveiros de Castro 1996; Lima 1996) comum a vários povos amazônicos, mas que procuro extrapolar para os Mbya Guarani, não sem ter sido levado a isto pela experiência etnográfica junto a eles que teve lugar nas aldeias de Mamanguá, Paraty Mirim, Araponga e principalmente Camboinhas (todas localizadas no estado do Rio de Janeiro), entre os anos de 2008 e 2013. Ao investigar de que modo os Mbya pensariam a humanidade dos animais, se impôs à reflexão a complementaridade entre dono e xerimbabo, par a partir do qual procuro aqui organizar uma noção mbya guarani sobre o ponto de vista.

\section{Condição humana e transformação em animal}

O tema em questão surgiu de várias formas durante meu trabalho de campo junto aos Mbya, desde a denominação Nhandejára ${ }^{2}$ (1 ${ }^{\text {a }}$ pess. pl.inc.+"dono") para as divindades até os relatos de -jepota ("transformação em animal") nos quais a pessoa se vê em processo de captura por algum dono de animal ou planta. Ao longo dos anos em que convivi com os Mbya, o fenômeno do -jepota sempre me chamou a atenção enquanto perigo constante e destino absolutamente indesejável para a pessoa. Logo, me surpreendi 
quando certa vez Minju, um de meus principais interlocutores na aldeia de Camboinhas, afirmou que o -jepota seria algo deixado por Nhanderu ${ }^{3}$ para que a pessoa vivesse um pouco mais, ainda que como bicho. Explicou então: "por isso que minha mãe fala tekoaxy para nós que estamos aqui pela Terra. Já eles lá em cima, não. Vamos supor assim: a galinha vê a gente como deus, mas já a gente não vê os Tupã Kuaray kuéry". A partir da comparação entre as relações animais/humanos e humanos/deuses, a condição tekoaxy que caracteriza esta Terra aparece, a um só tempo, como razão para a invisibilidade dos deuses e para a transformabilidade de humanos em animais.

As duas relações são conjugadas por Pissolato (2007:222) a partir de um certo descompasso entre a cosmologia e a sociologia mbya. Esta última, ao fazer consanguinidade e afinidade variarem nos diversos âmbitos das relações entre humanos, seria responsável por flexibilizar algo que aparentemente está bem definido na cosmologia, isto é, que a relação entre humanos e deuses é de consanguinidade e a relação entre humanos e animais de afinidade. Efetivamente, o -jepota aparece de modo privilegiado a partir do tema da união sexual com o animal, clímax de um processo anterior de sedução e apresamento do humano por uma subjetividade não humana.

Geralmente as narrativas versam sobre um encontro fortuito na floresta de um(a) jovem mbya com uma moça (ou um rapaz) de bela aparência, mas que na verdade é um animal. Seguem-se encontros que vão desfazendo a humanidade daquele(a) que está por se transformar: já não come mais na aldeia, não conversa muito, não participa das atividades rotineiras, em suma, "não se alegra mais" (ndovy'avéi). É no mato que ele(a) então se alegra, compartilhando alimentos - geralmente carne crua - com o(a) amante animal, e mantendo relações sexuais com ele(a). O processo é reversível, sendo necessário o trabalho do xamã que irá evocar a relação com os deuses a fim de trazer a pessoa de volta à condição humana. A consanguinidade com os deuses apareceria assim como uma forma de remediar relações marcadas por uma distância extremada, tal a (potencial) afinidade entre humanos e animais.

Mas o que orienta este súbito encantamento de pessoas mbya por pessoas-animais na floresta? Cadogan (1959:155) fala em "desobediência", isto é, o que se transforma em animal é aquele que imprudentemente não leva em consideração as falas e os conselhos de pessoas mais velhas. Montardo (2009:254) considera a audição como um sentido privilegiado do aprendizado para os Guarani, e de fato durante meu trabalho de campo era este sentido que era evocado pelos Mbya em referência à sabedoria (ou não) de pessoas e até de animais. Diziam de crianças que procediam a seus afazeres diários de acordo com pedidos e aconselhamentos dos mais velhos e que eram sábias 
(iarandu) por saberem ouvir (-endu kuaa). Crianças que procedessem de maneira contrária "não sabiam ouvir" e eram por isso qualificadas como não sábias (naiarandúi). Saber ouvir é uma qualidade extremamente valorizada entre os Mbya, enquanto seu contrário, ou seja, o descaso em relação ao que se escuta é origem e causa de comportamentos tidos como inadequados (-nhembotavy), como ter preguiça ou sentir raiva, ${ }^{4}$ por exemplo.

Idealmente se espera que todo mbya atualize todos os dias sua relação com as divindades - e aqui o sentido da audição é ainda fundamental e em certa medida quem não procede desta forma já está virtualmente em processo de transformação. Aspecto central do modo tekoaxy desta Terra em que se vive, esta seria a razão por que Minju dizia que o -jepota teria sido deixado por Nhanderu: recusando-se a viver de acordo com o que se escuta das divindades, estas reservam para a pessoa o destino da não humanidade: a transformação em animal é a forma limite do "não saber ouvir".

Dada esta forma, vários são os relatos de adoecimento ocasionados por um "mau comportamento" temporário que acarreta graus diferentes de transformação. De modo geral o convalescente deixa de comer (sua garganta, jyryvi, se fecha), perde peso, sente dores no corpo e assim por diante. Também pode escutar vozes e ficar mais distraído, descumprindo afazeres básicos e dando pouca atenção ao que se passa ao redor. Normalmente os Mbya falam desse processo em termos de captura, isto é, há uma potência querendo levar (-raa) a pessoa. Mas tal só aconteceria devido a comportamentos indevidos, ou como me disse Jéka, caso a pessoa não consiga "se segurar" (-jejoko), entenda-se, controlar ou conter de alguma forma o próprio desejo. Excedendo-se ela se torna alvo de desejo alheio.

Seguindo em meu diálogo com Minju, procurei entender melhor de que forma a galinha nos via, mas seu interesse não se voltava para o ponto de vista dela, mas sim para o dos deuses: "para nós o mar [...], é assim muito grande, mas para Nhandejára é tipo cachoeirinha que ele põe com um copinho. Então é assim, ele criou tudo, é o dono do mundo". A desigualdade entre o modo pelo qual a galinha percebe seus donos humanos e a maneira com que estes (não) veem os deuses constitui-se num exemplo perspectivista não muito típico, em que a grandeza que caracteriza o mar aos olhos humanos se transforma em pequenez aos olhos de Nhandejára, isto acontecendo justamente porque ele é dono em relação ao mundo.

Como as galinhas eram animais domésticos que não tinham maiores implicações simbólicas nas aldeias em que estive, me parece que o que Minju tentava pôr em evidência, ao utilizá-la como exemplo, era a equivalência entre as relativas posições de dono: humanos são donos de animais assim como Nhandejára é dono do mundo. Contudo, embora se trate de uma relação 
do mesmo tipo - entre um dono e coisas/seres possuídos por ele - os termos se distanciam ao passarmos do par humanos/animais para o par humanos/ divindades, já que a galinha nos vê enquanto nós não podemos ver os deuses. Dada esta distância maior, talvez a relação de consanguinidade ou filiação com os deuses professada pelos Mbya possa querer dizer outra coisa (sensu Viveiros de Castro 2011[2002]:407). Efetivamente, Fausto (2008:333) observa que se a categoria de dono exige um recíproco, este parece oscilar entre "filho" e "animal familiar", ambas contendo a ideia de adoção, ou de filiação adotiva, uma relação constituída pela dinâmica que o autor denominou de predação familiarizante.

Alguns autores têm estudado a relação com animais xerimbabos como algo a partir do qual se pode fazer uma leitura de aspectos relevantes da socialidade amazônica como as relações entre os sexos (Taylor 2000; Cormier 2003), a questão do "controle social" (Fausto 2008; Erikson 2012) ou a constituição do parentesco (Garcia 2010; Vander Velden 2010). Seria assim sensato passarmos a um comentário sobre os animais que durante o trabalho de campo foram alvo dos investimentos familiarizantes de meus interlocutores.

\section{Familiarização: causar alegria}

Os animais de estimação mais comuns em Camboinhas eram cães e gatos, os primeiros em maior quantidade. Os cães apareciam na aldeia vindos da rua ou trazidos por brancos, e eram adotados ou por alguém em especial ou pela comunidade. Apesar de animais desejados pelos Mbya, vez por outra era preciso haver uma espécie de controle da população canina, quando se desfaziam de algum animal, levando-o de carro para longe da aldeia e abandonando-o. Tal controle e ao que parece todo o cuidado seletivo que os Mbya de todas as aldeias em que estive parecem dedicar aos cães obedecem ao mesmo critério a que já me referi acima em relação a pessoas: se são iarandu ou naiarandúi. Os cães que latem à toa ou não são bons para caçar dificilmente serão alvo de cuidado, enquanto aqueles que se mostram "sábios" são bem tratados e bem alimentados.

Pierri (2013:219) ao chamar a atenção para o modo pelo qual os Mbya se referem ao cachorro, jagua, nota que este termo é também utilizado para anexar ferocidade a certos animais, como por exemplo: teju, lagarto, e teju jagua - "lagarto feroz" ou "lagarto monstro". Também comenta que, segundo seus interlocutores, o exemplar originário do cachorro é um animal de estimação de Tupã, que tem sua morada ao lado desta divindade. Aparen- 
temente por esta razão os cães só exercem sua ferocidade contra presas e inimigos dos Mbya, mas nunca contra os mesmos. Pierri (2013:220) sugere que o cachorro coloca para o pensamento indígena problema semelhante àquele que é colocado pelo queixada (cf. Lévi-Strauss, 2010 [1964]) "porque em ambos os casos está posta a possibilidade de domesticação de um ser agressivo". Tal como Tupã, os humanos possuem também sua fera doméstica.

Certa vez Iracema comentando sobre o porquê de se possuir um animal de estimação - e ela usava o cachorro como exemplo - explicou que às vezes Nhanderu ao pretender levar a pessoa (no sentido de causar sua morte) leva o mymba em seu lugar. Disse que as divindades escolheriam entre a pessoa e o animal, de modo que se pode às vezes viver pela morte de seu cão, o mesmo ocorrendo em relação aos filhos, já que estes seriam como mymba para os pais. Assim, desde que teve filhos não quis mais ter animais de estimação por temer tal "escolha" de Nhanderu, de modo que acabasse perdendo um filho em vez de um cão. Prefere assim não dar opção, não ter animais de estimação ou, dito de outro modo, ela os tem e são os seus filhos: "animal de estimação é do nosso coração que nós temos", comentou então. Não ter mymba para, desta forma, "ter bem" (-reko porã) os filhos seria assim uma tentativa de evitar que os deuses levassem um humano no lugar de um animal.

Os Karitiana (cf. Vander Velden 2010) que designam animais de criação e filhos da mesma forma, tornam especialmente evidente tal identidade durante o ritual funerário de cães de estimação. Foi dito para este autor (2010:174) que o ritual "se faz para que os filhos [humanos] do dono do animal não morram como o animal", por causa do suor da criança que brincava com o pet e que agora impregnaria seu cadáver. Se entre os Karitiana o perigo vem da consubstancialidade, entre os Mbya parece vir da convergência do ponto de vista de mymba com o de "gente", criança no caso.

Outro animal de estimação comum em Camboinhas era o mico $\left(k a^{\prime} i\right)$. Deste animal meus interlocutores diziam tratar-se de um bichinho dos filhos de deus, "aquele que é sábio, animal de estimação dos nhanderu mirim" como me disse Vera. Agái explicou-me que "o mico [causa] em nós sabedoria" e que "nossa alma vem do mico", afirmando que havia visto inclusive um desenho num livro ilustrando esta ideia. Ainda que este desenho, ao que tudo indica, tenha sido uma representação do esquematismo clássico da teoria da evolução das espécies numa forma-macaco evoluindo gradualmente para uma forma humana, de fato, algumas crianças mbya que nasceram com pelos nas costas foram consideradas como vindas "do mico mesmo" (ka'i gui ete). Se já vimos que humanos e animais de estimação nesta Terra podem ser "confundidos" pelos deuses, agora nos explicam que a alma, este duplo da pessoa, era um animal, ou melhor, um xerimbabo na terra dos deuses. 
Se Walker (2013:64) afirma que a predação familiarizante é generizada por natureza, e trabalhos como os de Taylor (2000), Cormier (2013) e Vander Velden (2010, 2012), entre outros, corroboram esta hipótese, o que observei entre os Mbya sobre a familiarização de micos é que ela operava uma diferença geracional: tratava-se de uma atividade realizada por crianças na maior parte das vezes, que andavam com o pequeno animal empoleirado em suas cabeças ou ombros, após ele já ter se acostumado na aldeia. Certa vez, em Camboinhas após convite de um menino para acompanhá-lo até sua casa, encontramos seu irmão bastante compenetrado, terminando de armar o gatilho de uma armadilha para pegar mico, utilizando-se de outro animal da mesma espécie como isca. Ao terminar, entregou a corda que acionaria a queda da porta da gaiola para Leti, sobrinha de ambos, alertando-a para que puxasse somente quando entrasse na gaiola o outro mico. Enquanto o animal hesitava em vir ao encontro do que servia de isca, outras crianças foram chegando e se interessando pelo evento. Leti logo passou a corda para Xivi, e foi ele quem acionou a armadilha quando o mico finalmente resolveu entrar na gaiola, trazendo-a em seguida para o pátio da casa de onde eu os observava. Após desamarrarem o animal que serviu de isca e deliberarem por alguns instantes, todos entraram em consenso: o mico capturado pertenceria a Xivi.

Aproveitei a ocasião para perguntar a Vera porque eles se utilizavam do expediente de amarrar e prender o bicho numa gaiola, ao que ele respondeu, "[quando] se alegrar/acostumar (ovy'a) aqui, nós soltamos novamente". Assim, após efetivada a captura é necessário o investimento contínuo na familiarização, pensada pelos Mbya como um processo de "alegrar" ou "acostumar" o animal com seu dono, com a casa, com a comida e com o ambiente humano. O mesmo verbo é também utilizado em relação a espécies vegetais cultivadas quando dão mostras de que vão "vingar", e também em relação à iniciação sexual de meninas, o que é traduzido como "amansar" (cf. Prates 2013). Especialmente em relação a este último contexto, compare-se com o que sugerem Taylor (2000) para os Jivaro e Walker (2013) para os Urarina sobre a associação entre mulheres e animais selvagens: ambos demandam certo investimento no sentido de sua domesticação.

Tal investimento é pensado aqui através da forma causativa do verbo -vy'a, isto é, "causar alegria" (-mbovy'a), um aspecto fundamental, portanto, da familiarização segundo os Mbya: alegria é um afeto central na composição do par dono/xerimbabo. Em sua reflexão sobre familiarização entre os Guajá, Garcia (2010) enumera algumas relações passíveis de serem lidas a partir do que caracteriza o par dono/xerimbabo para este povo: entre marido e esposa, entre seres humanos e animais, entre nominado e o que nomina, entre 
pessoas e seus duplos celestes, e outras. A chave para agrupar tais relações a princípio heterogêneas entre si está no verbo rikô, traduzido pelo autor como "criar": é dono aquele que "cria" outrem. Garcia (2010:262) mobiliza o dicionário Dooley da língua mbya a fim de exemplificar que também nela existiria o verbo reko, com o sentido de "criar", contudo não me parece que seja este o modo privilegiado através do qual os Mbya pensem a familiarização. Na verdade, o que se diz lá (Garcia 2010:267) sobre rikô - "no plano global, [...] está associado às múltiplas relações entre seres de diferentes ordens: celestes e terrestres, humanos e não humanos"- parece valer aqui justamente para a forma causativa de - $v y^{\prime} a$. Entre os Mbya o "selvagem" chega a ser "doméstico" através de esforços no sentido de "causar alegria" (ou "fazer acostumar") por parte dos que se colocam na posição de donos. Como vimos, só depois que o animal já se mostra "acostumado" ou "alegre", é que ele é solto e convive em liberdade com as pessoas na aldeia, sempre reconhecendo no dono uma fonte de alimentação e cuidado.

O tema do "alegrar-se" é frequente tanto nos contextos rituais (quando efetivamente se pede aos deuses que alegrem os humanos) quanto ordinariamente no dia a dia das aldeias. A alegria se faz a um só tempo razão e objetivo da vida: alegra-se enquanto se está (e por causa de estar) em busca de alegria, e esta é uma dimensão importante do parentesco mbya. Pissolato (2007:195), neste sentido, explica que "um não parente que chega e quer ficar é antes um parente em potencial que um estrangeiro. [...], numa aldeia nem todos se dizem parentes, mas devem viver como tal", ou seja, a partir de uma etiqueta que privilegia o bom humor e o "alegrar-se mutuamente" (-joguerovy'a). Assim se a alegria faz a passagem deste parente em potencial para o parente atual, isto é, um corresidente, a preocupação com modos de agir que desfazem o parentesco é constante, caracterizando o que a autora chama de sociabilidade insegura: se por um lado todo Mbya é parente em potencial, por outro, nenhum o é completamente (Pissolato 2007:213), e mesmo entre consanguíneos próximos atitudes agressivas e de antissocialidade podem vir a acontecer. Quando isto se dá, via de regra, sabe-se que o agressor age sob influência de outrem - donos, mortos etc.: se trata de "alguma coisa de ruim que se encaixa no corpo" da pessoa, como explicou Pedro.

Entre os Kanamari (cf. Costa 2013) a simetria que caracteriza a comensalidade e o afeto entre os habitantes de determinada aldeia surge a partir da relação assimétrica destes em relação a um chefe, o qual, por sua generosidade e capacidade de alimentar os demais é posto em posição de dono. O material mbya, por sua vez, nos permite sugerir que, dada a condição de dono do mundo das divindades, é a relação assimétrica destes em face dos 
humanos que faz surgir a alegria mútua entre corresidentes. Assim, em que pese a importância das funções de cacique e de xamã para a manutenção de um estado pessoal de alegria e satisfação em determinada aldeia, será sempre a partir de uma sensibilidade pessoal quanto ao que contam e fazem os deuses que se decidirá partir de ou ficar em lugares. Decisão fundamental, já que "não se alegrar" é um forte indício de que a pessoa está vulnerável, para dizer o mínimo, às potências maléficas de tekoaxy: ela pode estar morrendo, ou se transformando em bicho, o que é (quase) a mesma coisa.

\section{Motivando a ação dos donos}

O termo -ja é bastante comum no cotidiano mbya, porém dificilmente aparece relacionado a pessoas: fala-se em dono de instrumentos musicais, dono da porta da casa de reza (durante os rituais), dono da casa, dono de animais de estimação e até em dono de almas. Por outro lado, com seu recíproco, mymba, acontece o inverso. Lidia podia às vezes se referir às crianças pequenas da aldeia, seus netos via de regra, como "meus animais de estimação" (xerymba kuéry). Ouvi se referirem da mesma maneira aos próprios cônjuges, bem como, por parte de homens jovens a mulheres brancas cuja beleza lhes chamasse a atenção. ${ }^{5}$ Mas o que animais, crianças, cônjuges e belas mulheres estrangeiras teriam em comum para que se justificasse a comparação? Ao que parece, aquele que é posto numa posição mymba o é justamente enquanto potencial motivador para as ações alheias, sendo alvo de cuidados (alimentares, xamânicos etc.), de afetos (alegria, amor etc.), de ordens ("vá buscar lenha", "vá capinar" etc.) e de ação sexual (namorar, casar, engravidar, ${ }^{6}$ etc.). Haveria, neste sentido, uma potência motivante na posição mymba que faria dela alvo de cuidados, de ordens e fonte de prazeres. A agência desta posição, diríamos, é justamente mobilizar os que estão na posição de donos. Alguns trabalhos que tocam no tema das relações assimétricas na Amazônia chegam a conclusões semelhantes, como Bonilla (2005), Walker (2013), Gow (2001), Costa (2012; 2013), Vander Velden (2010), Kohn (2013) entre outros. Caminhamos assim ao encontro de estudos que se debruçam sobre as relações de maestria na Amazônia, sobre os quais Fausto (2008) já forneceu uma importante visão geral. ${ }^{7}$

Tais estudos vêm construindo uma "teoria das relações de não parentesco" (Viveiros de Castro, 2011 [2002]:153, grifo do autor) na Amazônia, a qual segundo Viveiros de Castro, partiria da afinidade potencial enquanto "fenômeno político-ritual" a englobar o parentesco, fazendo a ponte entre ele e o seu exterior. O autor fala em um "enselvajar-se" ao mesmo tempo em 
que se domestica o Outro (:290), como no caso da ligação entre o matador araweté e a alma de sua vítima, ou do guerreiro nivacle, que tem na alma do inimigo morto um traidor, que mantém o grupo do matador informado sobre os movimentos de seu grupo de origem, funcionando como "uma subjetividade exterior, selvagem que foi domesticada e desviada de sua natureza original" (:288). Em sua obra de maior fôlego, Fausto (2014 [2001]) denomina esse processo de "dialética senhor e xerimbabo", algo que aparece principalmente na relação xamânica dos Parakanã com inimigos oníricos que são familiarizados.

Em contraste com a concepção guarani que associa o canto xamânico à alma celeste, o autor nota que a esta reunião de homens e deuses se opõe a reunião dos Parakanã com inimigos ${ }^{8}$ e sua associação com potências predatórias (:354). Evidentemente, a ligação dos Mbya com as almas (nhe'ë kuéry) é aspecto crucial do modo como pretendemos desenhar a relação de maestria aqui e voltaremos a isto, mas é interessante notar que a análise de Fausto já sugeria que aquilo que ele chama de predação familiarizante poderia ser um instrumento eficaz para se pensar o vínculo dos Guarani com suas divindades, evidenciando mais uma teoria da pessoa do que da sociedade. Garcia (2010:268) comenta que o fato de o tipo de conexão que caracteriza a maestria (rikô) aparecer no pensamento guajá em esferas heterogêneas aponta para uma teoria da ação social "que não deve ser tomada como uma teoria dos indivíduos (ou da sociedade) mas, talvez, uma ontologia". Assim, a relação de maestria atua como um "operador cosmológico" (Viveiros de Castro apud Fausto, 2008:348) nesta dimensão ontológica da ação social, e isto tanto na Amazônia (como já demonstrado alhures), como também fora dela, argumento que ora defendo no presente trabalho.

Na literatura sobre os Mbya, a referência aos donos de animais e lugares do mato é tão frequente quanto de pouca fecundidade argumentativa, a não ser por algumas exceções, especialmente Heurich $(2008,2011)$ e Pierri (2013). Desde clássicos como Cadogan, Schaden, Chase-Sardi e outros, os donos figuram na cosmologia mbya (e guarani) como potenciais causadores de doenças, na maioria das vezes o -jepota. Na obra de Pissolato (2007) o tema é tratado através da noção de "andar junto", isto é, potências que passam a acompanhar a pessoa afetando seu agir, perigo ao qual pessoas que frequentam intensivamente lugares no mato estariam mais expostas. Mendes Júnior (2009:63) chama a atenção para o respeito como aspecto fundamental da relação com os donos: "tudo tem dono, se a gente mexer muito no rio, [...], o dono pode não gostar", diz-lhe um interlocutor. O mesmo autor (Mendes Júnior 2016) especifica duas razões principais para que pessoas mbya sofram retaliação por parte dos donos de animais: por caçarem em demasia 
ou por receberem dádivas constantes dos mesmos (quando se tem sucesso na pesca reiteradas vezes, por exemplo). Se na primeira parece atuar uma espécie de exigência de compensação pelas vidas animais subtraídas de modo excessivo, na segunda há o risco de que por ser alimentado por um desses donos a pessoa comece aos poucos a "se esquecer de seus parentes humanos e a desejar apenas a companhia daquele dono, o qual se lhe afigura como um belo cônjuge" (:147). A relação dos Mbya com os donos está, assim, fortemente implicada pela caça e pelo consumo de animais, de modo que se andar na companhia dos donos é algo negativo - trata-se efetivamente de um processo de adoecimento: manter alguma relação com eles é preciso.

Entre os Runa, povo da Amazônia equatoriana etnografado por Kohn (2013), os donos de animais parecem estar situados menos na posição ambígua de potencial agressor do que na de aliados virtuais. Através do uso de psicoativos os homens runa se comunicam com os donos estabelecendo elos (:144), entre os quais a relação amorosa com a filha de um dono por meio da qual se negocia a carne de animais a serem caçados. Pensados pelos Runa como "padres europeus ou brancos donos de propriedades" (:154), os donos são brancos possuidores de bens em abundância, principalmente animais domésticos de seu ponto de vista, mas que aparecem para os humanos como selvagens. Após a morte, uma pessoa runa vai "viver" com os espíritos donos, não como um igual, mas como cães de estimação deles, aparecendo então como jaguares para os viventes.

Ao organizarmos paralelamente as ideias mbya e runa relacionadas aos donos, veremos que elas se opõem simetricamente. Se entre os primeiros o distanciamento e o respeito estão associados à obtenção de carne e à aproximação excessiva (união sexual, no limite) ao abandono de modos humanos em um devir animal, entre os segundos dá-se o inverso: a carne de caça é garantida pela relação íntima entre um homem runa e a filha de um dono, estabelecendo-se então uma relação de afinidade. Mas há mais: a companhia de um dono pode levar à morte entre os Mbya, já entre os Runa é após a morte que se vai viver em companhia deles. Se entre os primeiros o xamanismo atua como possível reverso dos processos de adoecimento causados pelos donos, entre os segundos o xamanismo atua como uma possibilidade de comunicação com eles, justamente porque torna acessível aos homens o mundo tal qual visto por eles. Por fim, fala-se de um predicado runa de se ser simultaneamente predador e presa (idem:138), que se considerado para os Mbya nos levaria a pensar nas formas pelas quais se evita a condição de presa sem assumir ostensivamente a posição de predador, pois parece ser esta, justamente, a questão para eles. A solução reside na função motivadora com que já caracterizamos a posição de xerimbabo. Vejamos como esta função se exerce em outros povos amazônicos. 
Entre os Urarina (Walker 2013), as mulheres se colocam como pets em relação a seus maridos a fim de deles elicitar ações de proteção, ajuda, cuidado, fornecimento de bens e alimentos etc., e os homens, por sua vez, assumem atitudes de timidez e embaraço diante de vendedores brancos, fazendo com que se sintam na posição de terem que presenteá-los. O prestígio masculino se deve ao sucesso tanto na caça quanto nas trocas com os estrangeiros, e casamentos começam, muitas vezes, com a oferta de commodities por parte dos homens. Embora a mulher casada seja dita "domesticada" em face da solteira, Walker afirma que a despeito dos esforços masculinos elas nunca são completamente domesticadas, jamais perdem seu "aspecto terrível" (:60). De pets e mulheres se espera que mantenham sua "selvageria" e personalidade de modo que "estratégias para elicitar disposições de cuidado, benevolência e proteção nos outros poderiam ser vistas como centrais nas expressões de agência entre o povo urarina" (Walker 2013:60). Os Urarina (como os Paumari, que veremos a seguir) parecem apresentar a concepção assimétrica de si como "inferiores", "selvagens" ou mesmo "envergonhados" em contextos de relação com os brancos como algo estratégico a partir do qual se obtém vantagens.

Entre os Paumari (Bonilla 2005) a intenção de assumir a posição de freguês, investindo na transformação da relação com o Outro em uma do tipo comercial, é o que lhes permite escapar da posição de presa. As metáforas comerciais através das quais pensam suas relações de alteridade, fazendo coincidir seu ponto de vista com o de freguês, coloca-os em uma posição de presa domesticável. Escapam assim da exploração por parte de inimigos vorazes - os brancos, os quais passariam a assumir a posição de patrões domesticadores. Colocar-se na posição de freguês seria, para os Paumari, um tipo de estratégia predatória não apenas porque implica parasitar patrões brancos, mas também porque faz convergir seus esforços no sentido de colocar a relação em seus próprios termos: é o reposicionamento dos Paumari de presa para freguês que transforma inimigos/predadores em patrões domesticadores, ou bons patrões.

De um modo mais geral (e não mais especificamente na relação com os brancos), tal estratégia parece estar presente no modo de construção do parentesco kanamari, tal como apresentado por Costa (2013), no qual a noção de "dar de comer", aparece como a forma pela qual "a predação generalizada se converte em parentesco" (:495). Tendo em vista que o vínculo assimétrico entre o chefe de um grupo local e os demais corresidentes possibilita a simetria que caracteriza o parentesco em uma aldeia, Costa põe em relevo a imprescindibilidade da maestria para que se extraia parentesco de um fundo virtual de predação. ${ }^{9}$ Parte-se assim, como em muitos trabalhos 
recentes sobre as terras baixas sul americanas da conhecida tese de Viveiros de Castro (2011 [2002]:165) sobre a predação como princípio de relação das ontologias amazônicas. ${ }^{10}$

Entre os Mbya, como vimos, a construção do parentesco se dá pela atualização de relações orientadas pela "alegria", o que contrasta com a diversidade de potências maléficas espreitando do exterior do socius prontas para capturar a pessoa. Para escapar delas, os Mbya buscam sair da posição de presa fazendo coincidir seu ponto de vista com o de mymba das divindades, o que as provoca a agir em seu favor. Heurich (2008:56) e Pierri (2014:7-8) trazem dois exemplos de agenciamento de divindades por xamãs mbya sendo mediados pela ação maléfica de donos: respectivamente, um caso de transformação em planta e um caso de agressão a uma menina pelo dono da figueira. Se no primeiro exemplo um ritual xamânico envolvendo canto e dança exaustivos leva a cabo a cura, no segundo o mesmo ritual aciona atitudes mais contundentes por parte das divindades Tupã kuéry: além de curarem a menina, ainda fizeram secar a tal figueira. Em todo caso, ambos os autores deixam claro que a recuperação da perspectiva humana se dá através da ação xamânica de fazer agirem os deuses. Costuma-se ouvir de xamãs mbya, neste sentido, que não são eles que curam, mas sim as próprias divindades atuando através deles.

A ideia de que a perspectiva mbya coincide com a de animal de estimação dos deuses é encontrada de forma literal em uma passagem de A fala sagrada (P. Clastres 1990:129), na qual o xamã mbya Soria (em seu devir-Kuaray [Sol]) profere o seguinte: "vamos prestar atenção no movimento dos que enviamos, dos que habitam sobre a terra corrompida. Eles são nossos animais domésticos. ${ }^{11}$ Mas nós não devemos sentir o desejo de ser seus senhores". Nesta fala Soria/Kuaray qualifica a relação entre deuses e homens como de maestria e, ao ressaltar que os primeiros não devem sentir o desejo de ocupar a posição que é sua, põe em evidência o papel constitutivo da potência que caracteriza a posição mymba: se não cabe aos deuses sentir o desejo de serem "senhores" dos humanos, então deve ser próprio destes desejar estar na posição de mymba em relação àqueles. É o que parece indicar todo o esforço xamânico tanto de rezadores quanto dos corais de crianças mbya em "se fazerem ouvir" (-nhemonhendu) pelas divindades, "gritando" (-japukái) seus cantos-rezas: aliado a um comportamento que prioriza a escuta do que podem dizer os deuses haveria também o desejo de se fazer "ouvir", ser "percebido" ou "sentido" (-endu, nos três casos) por eles.

Os Mbya reivindicam em sua relação com os deuses algo que Gow (2001) diz estar intrinsecamente presente na socialidade piro, isto é, a possibilidade de, estando aflito, elicitar em outrem o sentimento de compaixão. 
Em comunicação pessoal, Mendes Júnior relatou-me que, certa vez, ao assistir a xamã Marciana (de Araponga) intercalar sua reza com lamentos e lágrimas, perguntou a Nino por que sua mãe procedia daquela maneira: "é para Nhanderu ter pena dela". Lidia explicou-me a origem de seus poderes xamânicos justamente sublinhando que Nhanderu teve compaixão (-mboaxy) dela após ter passado por muito sofrimento na vida. Pierri (2013:211) afirma que "mesmo que a relação entre as divindades e os Guarani seja pensada sob o signo da consanguinidade [...], a todo momento é preciso provocar esse sentimento de compaixão por parte dos deuses".

As divindades mbya, quando devidamente motivadas pelos humanos, atuam em seu favor, impedindo que outras subjetividades capturem seus corpos. Constituindo-se em "senhores" que não devem sentir o desejo de sê-lo, a ação dos Nhanderu precisa ser estimulada por um posicionamento singularizado dos Mbya, os "escolhidos" (porangue'i, segundo H. Clastres 1978 [1975]) ou "amados" (jeayu, de acordo com Cadogan 1959) dos deuses. Já que a condição de dono equivale à posição de sujeito em relação ao(s) xerimbabo(s), poder-se-ia concluir que os Mbya se pensam enquanto Outros dos deuses. ${ }^{12}$ Mas esta conclusão é bem menos poética do que a de Solano Karai Tataendy (Ortega et al. 2011[filme]): "nós somos bicicletas[de Nhanderu] mesmo... nada além disso".

\section{Os donos e a caça}

Certa vez, enquanto terminávamos o ritual diário na casa de reza em Camboinhas, escutamos ruídos estranhos vindo do sapê acima de nossas cabeças: logo suspeitaram da presença de algum animal. Saímos, e um dos jovens pegou um pedaço de pau para matar o que se constatou ser um ouriço, um pequeno mamífero. Após brevíssimo cerco seguido de abate, o corpo do animal foi levado diretamente para uma fogueira, para ser limpo e consumido no dia seguinte (já que costumeiramente não se comia à noite, principalmente carne). Não presenciei a não ser episódios fortuitos de caçada durante meu trabalho de campo, pois nesta aldeia não havia mata abundante nem, portanto, muitos animais disponíveis para serem caçados: vez por outra gambás e ouriços apareciam para serem logo abatidos com o primeiro pedaço de pau que estivesse à mão.

Contudo, aparentemente o método privilegiado pelos Mbya para a obtenção de carne é mesmo deixar armadilhas no mato - monde, mondepi, nhuã - e aguardar que nela caia algum animal. Mendes Júnior (2009:55) que foi treinado em Paraty Mirim em alguns dos princípios da caça põe 
em relevo o método mbya de verificação de armadilhas: "nos dias que se seguiram à construção do primeiro mondepi, Jango sempre dizia para que, pela manhã, eu fosse verificar se havia caído algum bicho". Frequentemente voltava o autor com animais de pequeno porte como gambá, guaki ou rato do mato. Dentre os animais capturados pelos Mbya, alguns são simplesmente comidos, enquanto outros são alvo de interesse familiarizante, na maioria das vezes mamíferos de maior porte como paca, capivara, queixada, bugio e também certos tipos de aves.

Quando estive na aldeia de Estiva (RS) visitando parentes dos Mbya de Camboinhas, observei a adoção de uma capivara, que vivia em seu cercado e era alimentada por seus donos, e que foi imediatamente consumida quando lhe sobreveio a morte natural. Em Araponga certa vez capturou-se um queixada, que também não foi imediatamente comido, mas sim adotado como mymba: vivia num cercado próprio durante o dia, onde era alimentado, e solto na aldeia durante a noite, quando chegava inclusive a entrar na casa de reza durante os rituais, algo que era vedado a outros mymba, como os cães, ${ }^{13}$ por exemplo. Com a morte acidental do animal, sua carne foi igualmente consumida. Soares (2009), ao descrever o processo de familiarização de bugios pelos Mbya do Rio Grande do Sul, chama a atenção para o fato de que lá, embora se evite consumir o animal adotado, assume-se a possibilidade de o mesmo servir de isca para outros indivíduos que, estes sim, seriam caçados e comidos.

Dizia-me Vhera Poty (comunicação pessoal), mbya da aldeia de Cantagalo (RS), que via de regra não se comem animais de estimação, porém quando comentei sobre o queixada de Araponga, ele afirmou, "queixada pode". Não parece, assim, ser possível afirmar que haja um consenso entre os Mbya sobre o consumo de animais familiarizados ou a sua evitação. Sabe-se, em todo caso, que cães e gatos jamais são consumidos, enquanto um tipo de carne é alvo de preferência: a de queixada (koxi). Mobilizaremos em seguida uma descrição de caçada a este animal apresentada por um informante de Cadogan (1971:98-9) a fim de demonstrarmos o lugar que ele ocupa no pensamento mbya.

O relato se inicia com o narrador saindo para verificar suas armadilhas. Encontra um veado que é prontamente abandonado quando percebe que mais adiante um queixada dava voltas no laço por ele deixado. O caçador celebra com um "canto ritual" (oguau), agradecendo respeitosamente aos donos do animal. Ao erguer o queixada, por este ser feito de "brilho de chamas", o narrador diz que teve os ombros descascados e queimados. $\mathrm{Na}$ aldeia, é recebido pelos seus com canto ritual e dança (kaï a'ã) e, após a distribuição das partes internas, as carnes propriamente ditas são colocadas 
nas panelas e os parentes são chamados para comer. Finalmente todos ficam alegres enquanto comem e agradecem àquele que tinha feito a armadilha - o "senhor dono do laço" (karai nhuã ja, 1971:100). Note-se que, desde o abandono de uma presa desejada como o veado em prol do queixada, até a recepção do animal abatido na aldeia, tão alegre quanto xamânica, com canto e dança, tudo parece indicar que este último é o favorito dos caçadores mbya, a presa entre presas. Veremos a seguir por que isto acontece.

A narrativa traz duas significativas analogias: 1) a alegria do caçador ao ver a presa na armadilha e a alegria dos corresidentes ao vê-lo chegar com o animal; 2) a gratidão do caçador para com os donos do animal, e a gratidão dos corresidentes para com o dono da armadilha. Alegria em receber, gratidão pela generosidade daquele que dá. Tudo parece indicar que ambos, dono do animal e dono da armadilha, se comportam sob a orientação de uma ética da reciprocidade e solidariedade, expressa comumente pelo termo mborayu. Se citamos acima casos de ações predatórias por parte de donos causando o adoecimento de pessoas mbya, na presente narrativa o que se tem é uma ação generosa do dono do animal. Tão generosa, aliás, quanto a postura do próprio caçador. Se Rivière (2001:49) afirma para o contexto guianense que "reciprocidade e predação [...] estão dispostas ao longo do mesmo espectro", diferindo entre si, não enquanto formas radicalmente diferentes de interação, mas em termos de conteúdo e contexto, a descrição acima parece revelar que, para os Mbya, a generosidade, fundamento da reciprocidade, é idealmente concebida como o próprio conteúdo da caça. Este seria, em suma, um dos contextos privilegiados de experimentação da generosidade alheia, donos dos animais caçados na maioria dos casos: “[se] cada [espécie] tem um dono é [este] quem nos dá" (Mendes Júnior 2009:59), explica Tereza, xamã da aldeia de Paraty Mirim.

Armar um laço ou um mundéu é uma forma de investir na caça enquanto dom, isto é, algo que é doado pelo dono do animal ou mesmo por Nhanderu. ${ }^{14}$ Neste sentido é preciso fazer jus ao que se recebe, não desperdiçando e aproveitando ao máximo a manifestação de generosidade alheia. O tratamento xamânico que certas carnes devem receber antes de serem consumidas (carne de queixada sendo uma delas) e o próprio respeito que se deve ter para com os donos, constituem-se em preocupações com uma possível retaliação por parte destes: os Mbya exibem extrema cautela quando se colocam na posição de predadores.

Certa vez, quando Xivi e Jéka pescavam em um rio de sua então futura aldeia, no município de Maricá (para onde se mudaram definitivamente em 2013), inúmeras vezes a rede foi recolhida excepcionalmente com abundância de peixes. Apressados em voltar para Camboinhas, os demais 
aguardavam pacientemente o fim da pescaria, que nunca se dava. Jéka explicou-me então que "o dono está dando, temos que aproveitar". Isto significava jogar a rede até que nenhum peixe caísse mais nela, o que em algum momento efetivamente aconteceu. Ou seja, é preciso ir até as últimas consequências da generosidade alheia, aproveitando ao máximo o que se recebe, sem contudo constituir uma relação efetiva de reciprocidade. Se é que se pode falar em troca, saber receber até o último quinhão é a parte que cabe aos Mbya em tal relação. Esta atitude é igualmente estratégica para que os Mbya capturem recursos fora do socius, e é comumente utilizada também em relação aos brancos (cf. Pereira 2014), donos que são de um mundo cheio de objetos e pessoas que são alvo do desejo mbya. Diz-se que não se pode recusar uma oferta sob pena de, ao fazê-lo, cancelar a generosidade alheia.

\section{Mymba porã: o queixada e o ponto de vista dos deuses}

O dono dos queixadas, contudo, parece ser uma singularidade dentre os donos de animais, e alguns relatos de interlocutores de Cadogan põem indiscutivelmente em evidência a sua posição privilegiada perante os demais animais: "apenas ele é um bom animal de estimação, os demais são apenas carne" (Cadogan 1971:64). No mito "Aquele que se transformou em queixada por ter desobedecido seu pai" (Cadogan 1959:155), o protagonista, ao se casar com uma mulher-queixada, tem Karai Ru Ete como sogro: trata-se de uma coincidência entre um dono de uma espécie animal e uma divindade mbya propriamente dita, um "Pai de almas" (Nhe'ë Ru Ete). O deus comporta-se então de maneira hiper-humana e, de forma mais do que generosa, alimenta o genro com farinha de amendoim eterno além de já ter lhe doado uma mulher (como vimos na nota 8, o cuidado de alimentar caberia justamente àquele que recebeu o cônjuge).

A correspondência entre queixada e animal de estimação de uma divindade, singulariza a distância entre o animal e o homem desde a relação com um terceiro termo: se um deus é dono dos humanos e é também dono do queixada, então humanos e animais podem ser pensados a partir de algum tipo de equivalência. Jéka, ressaltando a sabedoria e a humanidade do queixada, disse-me certa vez que o bando dorme ao redor dos filhotes a fim de protegê-los de eventuais ataques noturnos, e Vera chegou a dizer explicitamente que "porco é gente lá na terra de deus, só que aqui se mostra como bichinho", acrescentando que o caminho para a referida terra seria mostrado por este animal. Pierri, em nota (2013:218), comenta uma narrativa guarani na qual um queixada aparece para o protagonista como uma bela 
moça mostrando o caminho da morada dos Nhanderu Mirim, numa espécie de -jepota às avessas. Em sua análise da dieta alimentar preconizada para se alcançar o estado de imortalidade, o autor (:217-19) chama a atenção para o fato de que, ao contrário do que se afirmou durante muito tempo sobre o regime alimentar dos grandes xamãs, não se trata de uma dieta vegetariana, pois alimentar-se com carne de queixada constitui uma condição para o ijaguyje, estado de maturidade corporal que possibilita a ascenção à terra divina. A equação entre ambas as afirmações (de que "os queixadas são gente" e de que "é preciso comer carne de queixada para se alcançar o ijaguyje") resultaria erroneamente em uma atribuição de canibalismo (virtual) aos Mbya: sendo humanos e queixadas equivalentes de um certo ponto de vista, então a inclusão da carne destes últimos na dieta de alguém que busca a divinização poderia ser lida como uma prescrição canibal. Mas não iríamos tão rápido, até porque comer "gente" é o que comumente os ameríndios buscam evitar. ${ }^{15}$

Tanto ao queixada quanto a alguns outros animais caçados pelos Mbya é dispensado um tratamento xamânico de enfumaçamento do cadáver com tabaco - procedimento que evoca a preocupação mais geral entre os ameríndios de que toda carne continue sendo carne de gente (cf. Viveiros de Castro 1996). Através de cantos rituais e dança, mas principalmente por este "além-da-cozinha" (cf Lévi-Strauss 2010 [1967]:28), que é a fumaça do tabaco, os Mbya procedem ao cozimento prévio da carne, capaz de transformar o queixada de mymba dos deuses (posição na qual se identifica com os humanos), em animal próprio para o consumo. Se notarmos que, no contexto de cura de uma pessoa mbya, a fumaça atua como desanimalizante, ou seja, o "bicho" que a está atormentando não aguenta e sai de seu corpo (como me explicou Vera), podemos sugerir que atue de modo simetricamente oposto quando é utilizada em carnes de animais mortos: em relação a estes o que se busca afugentar é justamente sua humanidade. O mesmo procedimento é parte integrante do rito funerário mbya, ocasião na qual sua finalidade é afastar os mortos dos vivos, evitando que seu espectro incomode os que ficam. É preciso dispêndio de energia por parte dos Mbya tanto para afastar o perigo que os mortos representam quanto para transformar os queixadas em presas comestíveis.

Contudo, apesar de se equivalerem do ponto de vista dos deuses, como animais de estimação destes, humanos e queixadas diferenciam-se mutuamente. Enquanto a relação de cada um dos termos com os deuses os identifica, a relação deles entre si opera o movimento oposto: se para as divindades ambos são mymba, a ligação entre eles é perpassada pela mútua possibilidade de predação e de familiarização. Na verdade, a equivalência 
quanto ao dono que têm em comum parece ser origem e causa da diferença atual entre seus corpos, mas também origem e causa da possibilidade da transformação do humano em animal (e vice versa). Trata-se, assim, de uma atualização da perspectiva mítica, tornada eventualmente sensível aos corpos transformáveis dos Mbya. Não poderíamos opor o perspectivismo mbya ao amazônico aproximando-o de um perspectivismo asiático que Holbraad e Willerslev (2007) chamam de vertical ou transcedental, já que temos aqui justamente o que falta lá, isto é, "uma concepção de passado mítico de devir sem fim" (:336). A metamorfose em animal, que tem como condição o "fundo de continuidade subjetiva" (Fausto 2008:338) entre as espécies, é algo que, como vimos, preocupa os Mbya contemporâneos, e a leitura que fizemos da relação entre queixadas, humanos e deuses aponta para a assimetria como potência de atualização do mito, este "fora outro que o Estado" de que nos fala Lima (2011:634, grifo da autora).

Esta autora (:632) sugere que Pierre Clastres, em seus estudos sobre os Mbya, nos convida a entender a "divindade maior do panteão mbya [...] como um = multiplicidade, em cujo desdobrar desdobra-se a si mesma e as coisas em seu próprio desdobramento". Tal é a descrição da origem do universo segundo interlocutores de Cadogan (1959) e, após a criação de uma primeira terra que é destruída, o demiurgo Kuaray junto a seu irmão Jaxy é o principal operador das transformações que, nesta segunda terra, iriam definir nomes e formas de espécies animais e vegetais. Antes de alçarem seus corpos aos patamares celestes, os irmãos dão origem à onça, à paca, ao tamanduá, e assim por diante a depender do relato. O mito admite variações, como quando Vera me contou da seguinte maneira: "se vou para o céu, para ser deus, você chega para mim e fala 'me leva junto', mas [...] você não tem ainda força, eu falo, 'espera que eu volto pra te buscar', e você fica triste ou com raiva", e acrescentou ainda "o xivi (onça) era pessoa muito brava, e ficou com raiva" (Pereira 2014:181). Logo tornou-se o animal que é a encarnação máxima da predação para os Mbya.

No filme Nhande va'ekue meme'i: (Devos 2010) são narradas transformações míticas de alguns animais, sendo recorrente o tema da "quase divinização"16 como no exemplo do pássaro joão de barro que vivia somente dançando e rezando e quando estava quase atingindo a imortalidade encostou numa mulher e consequentemente transformou-se no animal que é hoje. ${ }^{17} \mathrm{O}$ mundo e o tempo das divindades são, de um só golpe, desejados e perigosos: ali está a imortalidade, a divinização da pessoa, mas também a possibilidade de "virar bicho". Fonte de vida e de morte, os Nhanderu seriam assim, dentre todos os predadores, potencialmente os maiores, como notou Macedo (2009:285) já que, seja através da identificação com 
"morcegos", "jaguares" e "trevas originais" (cf. Nimuendaju 1987), seja a partir do dilúvio que acabou com a primeira terra, a potência divina parece ser aquela do sujeito constituído internamente por diferenças, pois ainda que dadivoso de espécies vegetais, ${ }^{18}$ almas, corpos, em uma palavra, Vida, "Tupã será aquele que consumirá a terra em fogo" (Macedo 2009:285), ou como me disse Augustinho em Araponga, "quando os Tupã não quiserem ver mais esta Terra, cobrirão tudo [com água]". Tal ambiguidade, que já era comentada no início deste trabalho, nos leva a um breve comentário acerca da alma (nhe'ë), dimensão da imanência divina nos corpos mbya.

Augustinho explicou certa vez que a alma fica como que acoplada na pessoa na altura dos ombros mais ou menos, e quando se dança na casa de reza, sente-se um calor no alto da cabeça que indica sua ação, ou a ação dos deuses através dela: "os Tupã kuéry cuidam/vigiam nosso corpo, olham onde está a doença, onde você está se transformando em animal", e me deu pequenos beliscões no braço representando o ato (Pereira 2014:184). Nino, seu filho, disse ter sido salvo pelas almas quando no mato, durante colheita de mel, ao se proteger da queda de uma árvore do lado contrário do qual se esperava que ela caísse, de súbito foi avisado para andar alguns passos para o lado: o tranco da queda fez com que a parte inferior da árvore atingisse exatamente o lugar onde estava. Em uma exegese detalhada, Minju enumerou as almas em quatro: uma que fica junto da pessoa, outra que fica sempre na casa de reza, outra ainda que fica "lá em cima com o dono dela" e por fim uma que é um pequeno brilho que anda pelo mato de noite. ${ }^{19}$ Substância divina, a alma humana é ela mesma constante, não se transforma nunca, no máximo se afasta, abrindo espaço para aproximações perigosas. "Quando a pessoa erra muito - explicou-me Jéka - Nhanderu não quer ver e a alma deixa [o corpo]", fazendo convergir a perspectiva dos deuses e a da alma.

A noção mbya de alma evoca aquela entre duplos e carcaças/corpos, implicando uma "pessoa múltipla, replicada e distribuída" em uma "socialidade sociocósmica", descrita por Cesarino (2011:68-9) para os Marubo, mas que entre os Mbya teria a relação de maestria exercendo papel estruturante. As almas enquanto duplos que vivem nos patamares celestes com seus donos - os próprios deuses - ocupam o lugar de mymba destes por excelência. Buscar a identificação com a alma é buscar encurtar uma distância que, se sabe bem, jamais chegará a zero, restando para os humanos o movimento em tal direção, cujo término só pode se dar com a realização de uma impossibilidade: alcançar a terra divina com o corpo que se vive nesta Terra de sofrimento. Sendo o elemento que transita entre estes mundos, a alma define uma hiper-humanidade ao se aproximar do corpo da pessoa (caso dos xamãs, por exemplo) e um perigo de morte quando se afasta dele. 
Movimentos de aproximação e afastamento em relação aos corpos de pessoas mbya também caracterizam o deslocamento das potências causadoras de doenças, chamadas genericamente de "aqueles que não vemos" (jaexa e'ÿ va'e), as quais se busca todo o tempo manter afastadas. Foi exatamente nestes termos que Jéka me explicou a razão de se fazer estalar o chicote no pátio da aldeia ao entardecer, hábito comum em Camboinhas: "para que não se aproximem" (pono onhemboja). A possibilidade do -jepota é operada justamente por tais relações de afastamento e aproximação: da alma pessoal, da alma do animal ${ }^{20}$ ou de seu dono, do espectro dos mortos etc., de modo que a um corpo de gente é preciso corresponder uma alma de gente. Se esta se afastar, outras almas vêm tomar seu lugar redefinindo atitudes e afecções corporais, como por exemplo nos sintomas de adoecimento que enumeramos no início. Heurich (2015:535) descreve este mesmo fenômeno ao buscar os sentidos da embriaguez para os Mbya: "a cachaça não age somente como os mortos, pois atrai estes últimos para perto dos vivos-bêbados, e os faz virar mortos" (grifo do autor). Coincidência entre uma aproximação e uma transformação, a possibilidade de virar o que quer que seja parece ser pensada pelos Mbya de maneira privilegiada através de noções de distância, ${ }^{21}$ de modo que o ponto de vista efetivamente humano se dá pela proximidade da alma, e a possibilidade da sua perda acontece quando se aproximam outras subjetividades.

\section{Considerações finais}

Ativar nos deuses a potência de donos parece ser aspecto fundamental da experiência mbya, principalmente nas dimensões do parentesco e do xamanismo. Neste sentido, vimos que há uma série de medidas que visam alegrar e acostumar o animal familiarizado na aldeia, tal como o modo de vida orientado pelo que pode ser escutado dos deuses também alegra e faz acostumarem-se os corresidentes. O tom da convivência visto desta perspectiva, sendo o de alegrarem-se mutuamente, seria um instrumento eficaz para garantir a perspectiva humana sobre as relações entre pessoas que convivem diariamente.

E isto vale mesmo se se tratar de relações (intraaldeãs) com brancos, as quais, sendo cercadas por ambiguidades, exigem um investimento decisivo na familiarização destes: é preciso, como diz Silveira (2011), guaranizá-los, o que, num certo sentido, equivale a ensinar-lhes a alcançar uma perspectiva e ter um corpo semelhantes aos dos Mbya. O argumento poderia avançar ainda mais nesta direção, na qual me veria tendo que descrever e analisar o esforço 
de meus interlocutores no sentido de guaranizar a mim e a outros brancos que se fizeram íntimos deles durante sua permanência em Camboinhas e além. Destacaria então como nos era exigida a participação nos afazeres diários tanto quanto nos rituais cotidianos de reza-canto, e de algum modo concluiria que o que eles insistiam em nos ensinar era justamente como adquirir corpos mbya a partir de uma relação singular com os deuses. Tal exercício nos levaria à caminhada semelhante àquela que fizemos até aqui, e talvez até contribuísse com a presente ideia de pensar a coincidência entre o ponto de vista das divindades e o de dono dos humanos, já que tal coincidência parece justamente revelar uma questão fundamental do pensamento mbya, qual seja, a de imaginar o mundo segundo os deuses.

Recebido em 06 de junho de 2016

Aprovado em 15 de agosto de 2016

Vicente Pereira é docente de Magistério Superior na Universidade Federal de Alfenas, Alfenas/MG, Brasil E-mail: < vicentekaraimirim@gmail.com>

\section{Notas}

1 Agradeço à Valéria Mendonça de Macedo pela leitura cuidadosa da primeira versão deste texto.

2 Denominação, contudo, pouco corrente entre os Mbya, sendo bem mais comum o termo Nhanderu (1 ${ }^{a}$ pess.pl.inc. +"pai").

3 O termo, longe de revelar uma concepção monoteísta, funciona antes como uma designação genérica para uma variedade de coletivos de deuses: Tupã kuéry, Nhamandu kuéry, Nhanderu Mirim kuéry, Tupã Kuaray kuéry etc. A impressão é que há menos investimento na identificação destes coletivos (embora se reconheça eventualmente as atividades de alguns) do que na posição assimétrica dos deuses, de um modo geral, em relação aos humanos, daí o uso dos termos generalizantes Nhanderu ou Nhandejára.

4 Ambos sentimentos com uma subjetividade por detrás: o dono da preguiça (ateÿ ja) e o dono da raiva (vaija).

5 Também se diz que é mymba o pênis, e como apenas ouvi homens se referirem deste modo ao próprio órgão sexual, não saberia dizer se as mulheres também se utilizam do termo para falarem da vagina. Contudo escutei certa vez um jovem se referir a uma potencial amante como "dona do clitóris", kuï ja. 
6 O verbo "engravidar" (-mbopuru'a) é exclusivamente utilizado por homens, sendo formado pela partícula causativa mbo- e o estado de grávida (-puru'a). Assim, é o homem que causa a gravidez na mulher.

7 Em obra organizada recentemente (e que não teremos espaço nem fôlego para comentar aqui) Brightman, Fausto e Grotti (2016) reúnem artigos diversos de pesquisadores sobre o tema das relações de propriedade e cuidado na Amazônia.

8 O autor também comenta que o canto parakanã visa à permanência neste mundo enquanto o ñeengarai guarani se prestaria a "acompanhar a alma recém partida para o Além" (Fausto 2014 [2001]:354). O canto guarani, contudo, não é entoado somente em rituais funerários e tem, tal como concebido pelos Parakanã, a função de assegurar a permanência neste mundo ou "fazer durar a pessoa", ponto central do xamanismo (e do parentesco) mbya segundo Pissolato (2007).

9 A ideia de que o parentesco kanamari é construído a partir da evitação de relações de predação e canibalismo foi defendida pelo autor também tendo por base contextos de caça e consumo de animais (ver Costa 2012).

10 Sabe-se que o problema da afinidade na Amazônia orientou inicialmente o desenvolvimento do conceito de afinidade potencial e da noção de uma predação generalizada (cf. Viveiros de Castro 2011 [2002]). Se ali a figura conceitual do afim potencial é equacionada no pensamento mítico de sociedades uxorilocais de brideservice como um sogro ou cunhado canibal (:176), entre os Mbya (e Guarani), tal figura não está ausente (ver, por exemplo, Charïa apud Cadogan 1959 ou Anhã apud Nimuendaju 1987). No entanto, não se pode afirmar sobre outra regra de casamento além daquela que diz que se evitem parentes: o crédito canibal aqui é pago através de um serviço da noiva ou do noivo, dada a variação entre viri e uxorilocalidade: buscar lenha, servir chimarrão, caçar, mas também cozinhar, lavar louça etc. Ao que parece, algo equivalente a esta contrapartida em serviços prestados pelo genro que é o brideservice aparece no material mbya como um cuidado (-pena,-maë)) que genros e noras devem ter em relação aos sogros: faz-se necessário cuidar deles sob risco de não ser por eles cuidado, já que via de regra, as pessoas mais velhas $(\mathrm{G}+2)$ encarnam o poder xamânico, disponibilizando-o para a comunidade. É preciso, além disso, constância no cuidar, de modo a produzir parentesco, provocando cotidianamente nos sogros o desejo de cuidar deste parente em potencial (Pissolato 2007:195) que é o cônjuge dos filhos. Tudo parece indicar que entre os Mbya, como alhures, afinidade e diferença pertencem ao campo do inato, sendo a construção da consanguinidade "um processo necessariamente interminável de despotencialização" daquelas (Viveiros de Castro 2011 [2002]:423).

11 Não sendo dado ao leitor o acesso ao texto original, em mbya, poder-se-á questionar se o termo utilizado pelo xamã teria sido mesmo mymba. No entanto, posso afirmá-lo quase com certeza, já que não haveria, a princípio, na língua mbya uma forma específica de designar "animais domésticos" que os diferenciasse de "animais de estimação".

12 Tal conclusão ecoa a sugestão de Viveiros de Castro (2011 [2002]:281) sobre a condição do matador araweté em relação aos deuses: "[...] o que é um Iraparadï senão um Outro dos Outros, um inimigo dos deuses". 
13 Este dado não pode ser generalizado. Em Camboinhas, por exemplo, determinados cães entravam diariamente conosco na casa de reza, notadamente o mymba da xamã Lidia, mas também na de outras pessoas. Parece-me que quanto mais querido é o animal, mais apto está a entrar na casa.

14 Pierri (2013:206) assinala a concepção de que os animais que caem nas armadilhas já teriam sido "pagos" por Nhanderu, admitindo que "o idioma da predação e aquele das relações comercias são considerados equivalentes".

15 Argumentando em favor de uma pessoa ameríndia composta por partes predador e presa, Fausto (2007:513) sugere a distinção entre consumir o outro em sua condição de sujeito e consumi-lo em sua condição de objeto. Se a primeira forma de consumo remete ao canibalismo como devoração do outro em sua condição crua, isto é, como pessoa, a segunda exige a dessubjetificação da carne, geralmente através do cozimento.

16 Cadogan (1971:50) já observava que seriam poucos os Mbya que "não sabem de alguém que 'quase obteve agwyje'". Ao comentar o fracasso de um xamã mbya contemporâneo em alcançar o ijaguyje Pierri (2013:228-9) evoca o conhecido conjunto de mitos ameríndios denominados mitos da "má escolha" (cf. Lévi-Strauss 2010 [1964]) ao associar um "erro" do xamã à perda de oportunidade para o alcance da imortalidade.

17 Há também o motivo da desobediência: enquanto o demiurgo se punha a ensinar as danças, um homem foi para a floresta em busca de folhas de palmeira para fazer uma casa e, ao voltar, foi transformado em tamanduá (Cadogan 1959:84).

18 Milho, batata-doce, melancia, tabaco etc., apontados pelos Mbya como tendo sido deixados pelas divindades.

19 A esta última, quando avistada, os Mbya diziam ser preciso bater nela com chinelo ou pedaço de pau, pois caso encoste em alguém é causa de males. Como Augustinho disse ser este brilho o espectro dos mortos, estamos diante de uma noção de pessoa que inclui o contrário da pessoa, pois os mortos são inimigos dos vivos e desejam constantemente levá-los à sua condição.

20 Noto em tempo que embora alguns mbya promulguem uma falta de alma para os animais que em seu lugar teriam donos (ver Heurich 2008; 2011), na maior parte das vezes meus interlocutores admitiam que todos os animais possuem mesmo alma, nhe'ë.

21 Vale complementar aqui o que diz Heurich (2015:543) sobre a associação entre o estado de embriaguez $\left(-k a^{\prime} u\right)$ e a experimentação do ponto de vista dos mortos, pois o mesmo estado - $k a^{\prime} u$ se presta a descrever os efeitos do uso de tabaco no cachimbo: valoriza-se a capacidade dos xamãs de "aguentar" a fumaça e seus efeitos. A embriaguez apareceria assim como expressão de um trajeto que se percorre sem que se crie uma relação fundante que seja a identidade consigo mesmo (Fausto 2008:341). Se "o Si e o Mesmo não se confundem na construção da pessoa ameríndia", como diz o autor, a embriaguez incita um movimento na direção da Diferença que parece ser constituinte, seja na direção dos mortos, como descreve Heurich, ou na dos deuses, como no xamanismo. 


\section{Referências bibliográficas}

BONILLA, Oiara. 2005. "O bom patrão e o inimigo voraz; predação e comércio na cosmologia paumari". Mana: Estudos de Antropologia Social, 11(1):41-66.

BRIGHTMAN, Marc; FAUSTO, Carlos; GROTTI, Vanessa. 2016. Ownership and nurture: studies in native Amazônia property relations. New York: Berghan Books.

CADOGAN, Léon. 1959. Ayvu Rapyta: Textos míticos de los Mbya-Guarani Del Guaíra. São Paulo: Ed. USP. 1971. Yvyra ñe'ery: fluie del árbol la palabra. Asunción del Paraguay: Centro de Estudios Antropologicos de La Universidad Católica Nuestra Señora de Asunción.

CESARINO, Pedro de Niemeyer. 2011. Oniska: poética do xamanismo na Amazônia. São Paulo: Perspectiva/ Fapesp.

CLASTRES, Hélène. 1978 [1975]. A terra sem mal. São Paulo: Brasiliense.

CLASTRES, Pierre. 1990. A fala sagrada: mitos e cantos sagrados dos índios guarani. Campinas: Papirus.

CORMIER, Loretta.A. 2003. "Animism, cannibalism and pet-keeping among the Guajá of the eastern Amazonia". Tipití: Journal of the Society for the Anthropology of Lowland South America, 1(1):81-98.

COSTA, Luiz. 2012. "Making animal sinto food among the Kanamari of western Amazonia". In: Brightman, Grotti \& Ulturgasheva (eds.), Animism in rainforest and tundra: personhood, animals, plants and things in contemporary Amazonia and Siberia. Nova Iorque: Bergham Books. pp. 96-112.

. 2013. "Alimentação e comensalidade entre os Kanamari da Amazônia Ocidental". Mana: Estudos de Antropologia Social, 19(3):473-504.
ERIKSON, Phillipe. 2012. "Animais demais... Os animais no espaço doméstico matis". Anuário Antropológico II. Disponível em http://aa.revues. org.110. Acesso em 6 de dezembro de 2015. pp. 15-32.

FAUSTO, C., BRIGHTMAN, M., GROTTI, V. (eds). 2016. Ownership and nurture: studies in native Amazonian property. New York: Berghahn Books.

FAUSTO, Carlos. 2007. "Feasting on people: eating animals and human in Amazonia". Current Anthropology, 48(4):497-530.

. 2008. "Donos demais: maestria e domínio na Amazônia". Mana: Estudos de Antropologia Social, 14(2):329-366 .

2014 [2001]. Inimigos fiéis: história guerra e xamanismo na Amazônia. São Paulo: EDUSP.

GARCIA, Uirá Felippe. 2010. Kanamara: a caça e o mundo dos Awá-Guajá. Tese de Doutorado, Programa de Pós Graduação em Antropologia Social, USP, São Paulo, Brasil.

GOW, Peter. 2001. "Helpless: the afective preconditions of Piro social life". In: Joanna Overing; Alan Passes (eds.), The anthropology of love and anger: the aesthetics of conviviality in $\mathrm{Na}$ tive Amazonia. New York: Taylor \& Francis Library.

HEURICH, Guilherme. 2008. Yvyra'ija kuéry ha'egui ija kuéry regua: devir, conhecimento e aprendizado xamânico entre os Mbya-Guarani. Monografia, UFRGS, Rio Grande do Sul, Brasil.

2011. Outras alegrias: respeito e bailes mbya. Dissertação de Mestrado, Programa de Pós Graduação em Antropologia Social, Museu Nacional, UFRJ, Rio de Janeiro, Brasil. 
2015. "Outras alegrias: cachaça e cauim na embriaguez mbyá-guarani". Em Mana: Estudos de Antropologia Social, 21(3):527-552.

HOLBRAAD, M.; WILLERSLEV, R. 2007. "Transcendental perspectivism: anonymous viewpoints from Inner Asia". In: Thinking through things: theorizing artefacts ethnographically. London: Routledge. pp. 329-345.

KOHN, Eduardo. 2013. How forests think: toward na anthtropology beyond the human. London: University of California Press.

LÉVI-STRAUSS, Claude. 2010a [1964]. O cru e o cozido. São Paulo: Cosac Naify. . 2010b [1967]. Do mel às cinzas. São Paulo: Cosac Naify.

LIMA, Tania Stolze. 1996. "O dois e o seu múltiplo: reflexões sobre o perspectivismo em uma cosmologia tupi". Mana: Estudos de Antropologia Social, 2(2):21-47.

. 2011. "Por uma cartografia do poder e da diferença nas cosmopolíticas ameríndias". Revista de Antropologia de São Paulo, 54(2):601-646. MENDES JÚNIOR, Rafael Fernandes. 2009. Os animais são muito mais que algo somente bom para comer. Dissertação de Mestrado, Programa de Pós Graduação em Antropologia, UFF, Niterói, Rio de Janeiro, Brasil. . 2016. A saga rumo ao norte e os outros do caminho: a busca da terra sem mal entre os Guarani contemporâneos. Tese de doutorado, Programa de Pós Graduação em Antropologia Social, Museu Nacional, UFRJ, Rio de Janeiro, Brasil.

MACEDO, Valéria Mendonça de. 2009. Nexos da diferença: cultura e afecção em uma aldeia guarani na Serra do Mar. Tese de Doutorado, Programa de Pós Graduação em Antropologia, UNIFESP, São Paulo, Brasil.
MONTARDO, Deise Lucy Oliveira. 2009. Através do mbaraka: música, dança e xamanismo guarani. São Paulo: Editora da Universidade de São Paulo.

NIMUENDAJU, Curt Unkel. 1987. Mitos de criação e destruição do mundo como fundamento da religiáo dos Apapocuva guarani. São Paulo: Editora HUCITEC.

PEREIRA, Vicente Cretton. 2014. Aqueles que não vemos: uma etnografia das relações de alteridade entre os Mbya Guarani. Tese de Doutorado, Programa de Pós Graduação em Antropologia, UFF, Niterói, Rio de Janeiro, Brasil.

PIERRI, Daniel Calazans. 2013. O perecível e o imperecível: lógica do sensível e corporalidade no pensamento guarani mbya. Dissertação de mestrado, Programa de Pós Graduação em Antropologia Social, USP, São Paulo, Brasil.

. 2014. "O dono da figueira e a origem de Jesus: uma crítica xamânica ao ristianismo". Revista de Antropologia, 57(1):265-301.

PISSOLATO, Elizabeth. 2007. A duração da pessoa: mobilidade e parentesco e xamanismo mbya (guarani). Rio de Janeiro: NuTI.

PRATES, Maria Paula. 2013. Da instabilidade e dos afetos: pacificando relações, amansando Outros - Cosmopolítica mbyá-guarani (Lago Guaíba/RS, Brasil). Tese de Doutorado, Programa de Pós Graduação em Antropologia Social, UFRGS, Rio Grande do Sul, Brasil.

RIVIÉRE, Peter. 2001. "A predação, a reciprocidade e o caso das Guianas". Mana: Estudos de Antropologia Social, 7(1):31-53.

SILVEIRA, Nádia Heusi. 2011. Imagens de abundância e escassez: comida guarani e transformações na contemporaneidade. Tese de doutorado, Programa de Pós Graduação em Antropologia Social, UFSC, Santa Catarina, Brasil. 
SOARES, Mariana de Andrade. 2009. Entre índio e Bugios:conflito sócio-ambiental na região do Lami, Porto Alegre RS. VIII Reunión de Antropologia del Mercosul: Diversidad y poder en América Latina, Buenos Aires. Mimeo.

TAYLOR, Anne-Christine. 2000. "La sexe de la proie: représentations jivaro. Du lien de parenté". L'Homme, 154155:309-334.

VANDER VELDEN, Felipe Ferreira. 2010. Inquietas companhias: sobre os animais de criação entre os Karitiana. Tese de doutorado, Programa de Pós Graduação em Antropologia Social, UEC, São Paulo, Brasil.

\section{Filmes}

DEVOS, Rafael. Nhande va'ekue meme'i: os seres da mata e sua vida como pessoas. Prefeitura Municipal de Porto Alegre, 2010.
2012. "As galinhas incontáveis. Tupis, europeus e aves doméstica na conquista no Brasil". Journal de la Société des Américanistes. 98(2):97-140

VIVEIROS DE CASTRO, Eduardo. 2011 [2002]. A inconstância da alma selvagem: e outros ensaios de antropologia. São Paulo: Cosac-Naify. . 1996. "Os pronomes cosmológicos e o perspectivismo ameríndio". Mana: Estudos de Antropologia Social, 2(2):115-144.

WALKER, Harry. 2013. "Wild things: manufacturing desire in the urarina moral economy" Journal of Latin American and Caribbean Anthropology, 18(1):51-66.

ORTEGA, Ariel; FERREIRA, Patricia; BEÑITES, Germano; MORINICO, Jorge. (Coletivo Mbya Guarani de Cinema). 2011. Bicicletas de Nhanderu. São Miguel das Missões, RS. 
NOSSO PAI, NOSSO DONO:

RELAÇÕES DE MAESTRIA ENTRE OS MBYA GUARANI

\section{Resumo}

O presente artigo discute a relação de maestria a partir do contexto etnográfico mbya guarani, propondo um diálogo entre a etnologia sobre este povo e a amazônica, buscando uma aproximação entre certas concepções mbya e o perspectivismo ameríndio. A indesejada possibilidade de "transformação em animal" (-jepota), os contextos de caça e o investimento na familiarização de alguns animais indicam de que ponto de vista os Mbya pensam a humanidade destes, constituindo uma modulação do perspectivismo na qual a relação de maestria tem papel estruturante. Através da relação entre dono e xerimbabo os Mbya operam um reposicionamento de si mesmos, passando de potenciais presas de entes maléficos atuantes nesta Terra a animais de estimação dos deuses, amados e protegidos por eles.

Palavras-chave: Maestria; Perspectivismo; Mbya Guarani.
NUESTRO PADRE, NUESTRO DUEÑO: RELACIONES DE MAESTRÍA ENTRE LOS MBYA GUARANÍ

\section{Resumen}

El presente artículo discute la relación de maestría a partir del contexto etnográfico mbya guarani buscando un diálogo entre la etnología acerca de este pueblo y la amazónica, acercando ciertas concepciones mbya del perspectivismo amerindio. La indeseada posibilidad de "transformación en animal" (-jepota), los contextos de caza y el tiempo invertido en la familiarización de algunos animales indican a partir de que punto de vista los Mbya piensan la humanidad de estos, constituyendo una modulación del perspectivismo en la cual la relación de maestría tiene un rol estructurador. A través de la relación entre dueño y xerimbabo los Mbya se reposicionan a sí mismos, pasando de potenciales presas de malas potencias de esta Tierra a animales de estimación de los dioses, amados y protegidos por ellos.

Palabras clave: Maestría; Perspectivismo; Mbya Guarani. 
OUR FATHER, OUR OWNER:

MASTERY RELATIONS AMONG THE MBYA GUARANI

\section{Abstract \\ This article discusses mastery relations among the Mbya Guarani. It proposes a bridge between Guarani and Amazonian ethnology by approximating certain Mbya concepts to Amerindian perspectivism. Through an investigation of the}

dangerous possibility of "transforming into an animal" (-jepota), hunting and the familiarization of certain animals, the article reveals how the Mbya conception of the humanity of animals is a variant of perspectivism in which mastery relations play a structuring role. Shifting from the potential prey of evil earthly beings to the pets of the gods, the Mbya are able to reposition themselves as the objects of divine love and protection.

Key-words: Mastery; Perspectivism; Mbya Guarani. 